\title{
Planejamento, desenvolvimento e avaliação de um Ambiente Virtual de Aprendizagem gamificado
}

\author{
Isadora Lopes Barbosa Vasconcellos - IFFluminense - ivasconcellos@iff.edu.br \\ Annabell Del Real Tamariz - UENF - annabell@uenf.br \\ Silvia Cristina Freitas Batista - IFFluminense - silviac@iff.edu.br
}

\begin{abstract}
Resumo: $O$ presente artigo tem como objetivo descrever o planejamento, o desenvolvimento e a avaliação de um Ambiente Virtual de Aprendizagem (AVA) gamificado, que visa ampliar a motivação e o engajamento dos alunos. Após serem elencados e desenvolvidos os recursos de gamificação do AVA, foi elaborado um curso sobre Lógica de Programação para alunos de um curso Técnico de Informática, tendo em vista a experimentação do ambiente. Antes da efetivação do curso, foi realizada uma avaliação da usabilidade do AVA e da adequação dos materiais instrucionais aos princípios da Teoria Cognitiva da Aprendizagem Multimídia e ao público-alvo. Os dados, coletados por questionários e analisados qualitativamente, sinalizaram resultados positivos e as sugestões contribuíram para o aprimoramento do AVA e dos materiais.
\end{abstract}

Palavras-chave: gamificação. ambiente virtual de aprendizagem gamificado. gamificação na educação.

\section{Planning, development and evaluation of a gamified Virtual Environment Learning}

\begin{abstract}
The purpose of this article is to describe the planning, development and evaluation of a gamified Virtual Learning Environment (VLE), which aims to increase the motivation and engagement of students. After the gamified VLE resources were listed and developed, it was designed a course on Programming Logic for students of a Computer Technician course, for experimentation of the environment. Before the execution of the course, it was carried out an assessment of the usability of the VLE and the appropriateness of the instructional materials to the principles of the Cognitive Theory of Multimedia Learning and to the target audience. The data, collected by questionnaires and analyzed qualitatively, signaled positive results and the suggestions contributed to the improvement of VLE and materials.
\end{abstract}

Keywords: gamification. gamified virtual learning environments. gamification in education.

\section{Introdução}

O desenvolvimento, a evolução e a ampliação do acesso às tecnologias digitais e à Internet têm promovido diversas mudanças na educação, dentre as quais pode ser citada a propagação de cursos online e híbridos (com momentos online e presenciais). Para dar suporte a esses cursos, surgiram diversos softwares conhecidos como Ambientes Virtuais de Aprendizagem (AVAs). Os recursos disponibilizados variam de acordo com o AVA e visam auxiliar e promover o processo de ensino e aprendizagem, tais como: fóruns, chats, quadros de avisos, inserção de diversos tipos materiais instrucionais, glossários, questionários, entre outros.

Contudo, Bissolotti et al. (2014) ressaltam que muitos professores ainda utilizam os AVAs apenas como repositórios de materiais didáticos, fazendo com que alguns perfis de alunos, acostumados com mais estímulo no dia a dia, sintam-se entediados e desestimulados ao ter que estudar neste tipo de ambiente. Desta forma, é importante que 
sejam utilizadas ferramentas mais imersivas nos AVAs, sendo a inserção da gamificação uma das propostas para se atingir este objetivo.

De acordo com Fadel et al. (2014), a gamificação é a utilização de sistemáticas e mecânicas do ato de jogar, percebidas como elementos prazerosos e desafiadores, em um contexto fora de jogo, com o propósito de envolver emocionalmente os indivíduos, provendo um ambiente propício ao engajamento destes. Alves (2015) ressalta a relevância da gamificação na educação ao expor que novos desafios e cenários exigem novas posturas e respostas que contribuam para a aprendizagem efetiva, tendo a gamificação se mostrado como uma das propostas para promover a aprendizagem.

No entanto, deve-se ter uma preocupação para que a utilização de elementos de gamificação e de materiais instrucionais multimídia não promova uma sobrecarga cognitiva nos alunos. Para Tarouco et al. (2017), o desafio da aprendizagem com materiais multimídia é fazer com que os alunos construam representações mentais significativas, sem serem sobrecarregados com informações irrelevantes. Visando evitar esta sobrecarga, a Teoria Cognitiva da Aprendizagem Multimídia (TCAM) possui 12 princípios para auxiliar na elaboração de materiais multimídia (Mayer, 2011). Logo, os princípios da TCAM podem servir como guia aos educadores no processo de criação destes materiais, pois a utilização dos seus princípios ajuda a equilibrar as cargas cognitivas dos alunos, favorecendo a aprendizagem (Tarouco et al., 2017).

Diante desse contexto, este artigo tem como objetivo descrever o planejamento, o desenvolvimento e a avaliação inicial do AVA gamificado AGILE ${ }^{1}$ (Attractive, Gamified and Interactive Learning Environment - Ambiente de aprendizagem atrativo, gamificado e interativo), por meio de uma pesquisa qualitativa do tipo exploratória. A avaliação inicial teve como foco a análise da usabilidade do AVA e da adequação do material instrucional do curso sobre Lógica de Programação, elaborado para experimentação do AGILE, aos princípios da TCAM e ao público-alvo. Esta avaliação, portanto, foi realizada antes da experimentação do AGILE com o público-alvo da pesquisa, que são os alunos do curso Técnico de Informática do campus Campos Centro do Instituto Federal de Educação, Ciência e Tecnologia Fluminense (IFFluminense).

Com a utilização do AGILE, busca-se ampliar a motivação e o engajamento dos alunos durante o processo de aprendizagem, sem promover uma sobrecarga cognitiva a partir da utilização dos recursos disponibilizados. Além disso, almeja-se prover, para os professores, uma ferramenta gamificada que seja de fácil utilização e que permita a autoria destes nos conteúdos abordados. O processo de planejamento, de desenvolvimento e a avaliação inicial do AGILE e do curso, assim como a fundamentação teórica adotada, são abordados nas seções a seguir.

$\mathrm{Na}$ Seção 2, é contextualizada a gamificação, sua aplicação em AVAs e a importância da usabilidade nestes ambientes. Na Seção 3, caracteriza-se a TCAM e, na Seção 4, é descrita a metodologia utilizada na pesquisa. Na Seção 5, são analisados os resultados obtidos e, por fim, na Seção 6, são apresentadas as considerações finais.

\section{Gamificação e Ambientes Virtuais de Aprendizagem}

A gamificação não é a utilização de um jogo, mas de mecânicas, estéticas e pensamentos baseados em jogos para engajar pessoas, motivar a ação, promover a aprendizagem e resolver problemas (Alves, 2015). Flores et al. (2016) conceituam gamificação como o uso de elementos e design de jogos para melhorar a experiência e o engajamento do usuário em aplicações e ambientes que não são jogos.

De acordo com Kapp (2012), existem dois tipos de gamificação: estrutural e de conteúdo. A gamificação estrutural utiliza elementos de jogos para conduzir o aprendiz 
pelo processo de aprendizagem sem que haja alterações significativas no conteúdo, logo o conteúdo não se torna parecido com um jogo, mas a estrutura ao redor do conteúdo é modificada para parecer um jogo. Já a de conteúdo utiliza elementos e pensamentos de jogos para alterar o conteúdo a ser aprendido, de modo a fazer com que este seja moldado com mecanismos de jogos, ou seja, se pareça com um jogo (Kapp, 2012).

$\mathrm{Na}$ educação, a gamificação tem sido utilizada para aumentar a motivação, a interação e a satisfação dos alunos com as atividades propostas (Flores et al., 2016). Essa também tem se mostrado cada vez mais presente nos AVAs. Uma pesquisa realizada por Klock et al. (2014) analisou a gamificação em dez AVAs: Khan Academy, PeerWise, QizBox, BrainScape, Peer2PeerUniversity, URI Online Judge, CodeSchool, Duolingo, Passei Direto e MeuTutor. Os pesquisadores identificaram que, das 11 mecânicas de jogos mais comuns elencadas na literatura, apenas seis estavam presentes nestes ambientes, que foram: pontos, medalhas, missões, personalização, níveis e rankings (Klock et al., 2014). As outras cinco mecânicas que haviam sido elencadas, mas não encontradas nos AVA, foram: loops de engajamento, reforço e feedback, integração, regras e narrativa. Já a pesquisa realizada por Brazil e Baruque (2015), explanou que a maioria dos AVA gamificados possuem mecânicas conhecidas como PBL (Points, Badges and Leaderboards - pontos, medalhas e quadro de líderes).

Contudo, é importante mencionar que a quantidade de recursos de gamificação do AVA não define sua efetividade no processo de aprendizagem, o essencial é como estes recursos são utilizados. Ogawa et al. (2015) destacam que para que a gamificação produza o efeito esperado, é necessário considerar o conteúdo a ser aprendido, as características dos estudantes e as tarefas disponíveis no AVA. De acordo com Toda et al. (2017), é necessário realizar um bom planejamento do contexto em que a gamificação será aplicada. Desta forma, considera-se que para aumentar as chances de sucesso na utilização dos AVAs gamificados, é necessário um adequado planejamento tanto dos recursos como dos materiais instrucionais utilizados.

Outro aspecto a ser considerado para a efetividade da aprendizagem nos AVAs é a usabilidade (Souza, 2018). Da perspectiva de sistemas de informação, Nielsen (2012) explana que a usabilidade é um atributo de qualidade de software responsável por avaliar como as interfaces gráficas são fáceis de serem utilizadas pelos usuários. $\mathrm{O}$ Quadro 1 apresenta os cinco componentes da usabilidade, segundo Nielsen (2012).

Quadro 1 - Componentes da usabilidade

Componentes da usabilidade

\begin{tabular}{|c|l|}
\hline \multicolumn{2}{|c|}{ Componentes da usabilidade } \\
\hline $\begin{array}{c}\text { Capacidade de } \\
\text { aprendizado }\end{array}$ & $\begin{array}{l}\text { O sistema deve permitir que os usuários realizem facilmente tarefas básicas na } \\
\text { primeira vez que este for utilizado. }\end{array}$ \\
\hline Eficiência de uso & $\begin{array}{l}\text { Uma vez que os usuários tenham aprendido a utilizar o sistema, estes devem ser } \\
\text { capazes de executar as tarefas com rapidez e produtividade. }\end{array}$ \\
\hline $\begin{array}{c}\text { Facilidade de } \\
\text { memorização }\end{array}$ & $\begin{array}{l}\text { O sistema deve possuir recursos que o tornem fácil de ser memorizado para que, } \\
\text { após algum tempo sem utilizá-lo, os usuários se recordem do seu funcionamento. }\end{array}$ \\
\hline $\begin{array}{c}\text { Baixa taxa de } \\
\text { erros }\end{array}$ & $\begin{array}{l}\text { O sistema deve prever e evitar que os usuários cometam erros e, caso estes } \\
\text { ocorram, deve permitir uma rápida recuperação por meio de instruções simples. }\end{array}$ \\
\hline Satisfação & O sistema deve possuir design e recursos que sejam agradáveis aos usuários. \\
\hline
\end{tabular}

Fonte: Nielsen (2012) - adaptado.

Os problemas de usabilidade em AVAs possuem grande relevância, pois podem comprometer a realização de tarefas e, assim, prejudicar o processo de construção do conhecimento. Para Souza (2018), um AVA com boa usabilidade é fácil e agradável de ser utilizado e essa facilidade depende, principalmente, da organização lógica das informações que serão disponibilizadas. Este autor também ressalta que, mesmo que a qualidade da interface gráfica não seja o aspecto principal de um AVA, esta faz parte da interação entre o usuário e o AVA, impactando no processo de aprendizagem. 
Penna et al. (2015) realizaram uma análise do AVA Moodle de uma instituição privada de ensino fundamental tendo como base a técnica de avaliação heurística da usabilidade de Nielsen. Inicialmente, foram encontrados 16 problemas de usabilidade, sendo os principais: i) a ausência de mensagem de feedback quando ocorre algum erro; ii) a presença de informações desnecessárias; e iii) a ausência de elementos importantes para a interação do usuário (botões, links, etc.). Nota-se que os principais componentes da usabilidade afetados foram a baixa taxa de erros (i) e a eficiência em uso (ii e iii).

Já a pesquisa realizada por Zago e Polino (2016) sobre a usabilidade no AVA Moodle da Universidade Federal de Pelotas, também utilizando a técnica de avaliação heurística da usabilidade de Nielsen, mostrou que os principais problemas existentes eram: i) a organização confusa dos recursos do AVA; ii) a existência de informações redundantes; e iii) a interface gráfica não intuitiva. Assim, observa-se que os principais problemas encontrados afetavam, principalmente, o componente de eficiência em uso.

\section{Teoria Cognitiva da Aprendizagem Multimídia}

A Teoria Cognitiva da Aprendizagem Multimídia (TCAM) descreve como as pessoas aprendem a partir de instruções em formato multimídia (Mayer, 2003). De acordo com Mayer (2003), uma mensagem instrucional multimídia é uma apresentação formada por palavras e imagens com o propósito de promover a aprendizagem significativa. As palavras podem ser impressas ou faladas e as imagens podem ser estáticas, como ilustrações e gráficos, ou dinâmicas, como vídeos e animações.

A TCAM possui 12 princípios, elaborados com base em evidências científicas, que têm como propósito auxiliar a elaboração e/ou a escolha de materiais instrucionais, em formato multimídia, a fim de promover melhores resultados no processo de ensino e aprendizagem. Tais princípios são descritos no Quadro 2 (Mayer, 2011).

Quadro 2- Princípios da Teoria Cognitiva da Aprendizagem Multimídia

\begin{tabular}{|c|c|}
\hline Princípios & De acordo com cada princípio, pessoas aprendem melhor: \\
\hline 1. Princípio de Coerência & quando palavras, imagens e sons estranhos são excluídos. \\
\hline 2. Princípio de Sinalização & $\begin{array}{l}\text { quando são adicionados recursos que destacam a organização do } \\
\text { material essencial. }\end{array}$ \\
\hline 3. Princípio da Redundância & $\begin{array}{l}\text { com animação e narração do que com animação, narração e texto } \\
\text { na tela. }\end{array}$ \\
\hline $\begin{array}{l}\text { 4. Princípio de Contiguidade } \\
\text { Espacial }\end{array}$ & $\begin{array}{l}\text { quando as palavras e as imagens correspondentes são } \\
\text { apresentadas próximas umas das outras. }\end{array}$ \\
\hline $\begin{array}{l}\text { 5. Princípio da Contiguidade } \\
\text { Temporal }\end{array}$ & $\begin{array}{l}\text { quando as palavras e as imagens correspondentes são } \\
\text { apresentadas simultaneamente e não sequencialmente. }\end{array}$ \\
\hline 6. Princípio de Segmentação & $\begin{array}{l}\text { quando uma lição multimídia é apresentada em segmentos, de } \\
\text { acordo com ritmo do usuário, e não como uma unidade contínua. }\end{array}$ \\
\hline 7. Princípio do Pré-treino & $\begin{array}{l}\text { quando, em uma lição multimídia, conhecem os nomes e } \\
\text { características dos principais conceitos. }\end{array}$ \\
\hline 8. Princípio da Modalidade & com animação e narração do que com animação e texto na tela. \\
\hline 9. Pricípio Multimídia & com palavras e imagens do que somente com palavras. \\
\hline 10. Princípio da Geração & $\begin{array}{l}\text { com lições multimídia quando elas geram palavras ou desenhos } \\
\text { ou se autoexplicam durante o aprendizado. }\end{array}$ \\
\hline 11. Princípio da Personalização & $\begin{array}{l}\text { quando, em lições multimídia, as palavras estão no estilo de } \\
\text { conversação, e não no estilo formal. }\end{array}$ \\
\hline 12. Princípio da Voz & $\begin{array}{l}\text { quando a narração em lições multimídia possui uma voz humana } \\
\text { amigável em vez de uma "voz de máquina". }\end{array}$ \\
\hline
\end{tabular}

Fonte: Mayer (2011, p. 90, 94, 99) - adaptado.

Na pesquisa de Almeida et al. (2014), foi realizada a avaliação de 10 objetos de aprendizagem (OAs), em diversos formatos multimídia, sobre o sistema digestório, tendo como base os princípios da TCAM. A pesquisa mostrou que apenas o princípio da Contiguidade Espacial se mostrou adequado em todos os OAs. Foram encontrados 
problemas como a repetição da informação na forma narrada e escrita; conteúdos apresentados de forma muito extensa; presença de palavras ou sons que não agregavam valor ao conteúdo ensinado; e ausência de sinalização para direcionar a atenção do aluno para elementos importantes nos textos e nas imagens.

Já a pesquisa realizada por Neves et al. (2016), sobre a adequação das imagens referentes ao conceito de "célula" em livros de Biologia do Ensino Médio e do Ensino Superior em relação aos princípios da TCAM, indicou a presença de problemas com os princípios da Coerência, Sinalização e, principalmente, Contiguidade Espacial.

\section{Metodologia da pesquisa}

A descrição da metodologia utilizada no planejamento, desenvolvimento e avaliação inicial do AVA AGILE foi dividida em três subseções, apresentadas a seguir.

\subsection{Planejamento}

A pesquisa foi iniciada com uma revisão da literatura, em artigos científicos, visando identificar os recursos de gamificação mais utilizados. Dessa forma, foram identificados seis recursos principais: i) pontos de experiência; ii) evolução de níveis; iii) recompensas; iv) metas; v) rankings de líderes; vi) sistemas de feedback.

Em seguida, foi realizada uma pesquisa exploratória em alguns AVAs com o propósito de identificar se possuíam recursos de gamificação e o funcionamento destes. De acordo com Gil (2008), a pesquisa exploratória tem como objetivo desenvolver, esclarecer e modificar conceitos e ideias, visando à formulação de hipóteses ou problemas que serão pesquisados futuramente. Os AVAs escolhidos para pesquisa foram: Schoology, Edmodo, ClassCraft, Khan Academy e Pluralsight. A escolha dos AVAs teve como critério menções a estes nos artigos científicos analisados inicialmente.

Durante a pesquisa, foi verificado que no Schoology e no Edmodo há a possibilidade de distribuição de medalhas pelas atividades realizadas e comportamento dos alunos, porém este processo não é automatizado, devendo o professor analisar se o aluno realizou a ação conforme o esperado para, em caso afirmativo, atribuir a medalha.

Já no Classcraft há diversos recursos de gamificação como criação de personagens, narrativa, desafios, fichas de atributos dos personagens, entre outros. No entanto, este é voltado para uso em sala de aula presencial, os recursos mais avançados não são gratuitos e também é necessário que o professor adicione e desconte manualmente as pontuações dos alunos. No Khan Academy, verificou-se a presença de recursos mais automatizados de gamificação para distribuição de pontos e badges, porém não é possível que o professor crie um curso de própria autoria, devendo este selecionar os conteúdos e as atividades já existentes no AVA para montar o curso. O Pluralsight também possui recursos de gamificação automatizados, mas o aluno se inscreve em um curso com estrutura e conteúdo já definidos no AVA.

Verificou-se que os recursos de gamificação destes AVAs utilizavam apenas mecânicas mais simples de jogos, como pontos, medalhas e rankings de líderes e que, em alguns casos, estes recursos não eram automatizados, dependendo da intervenção do professor (Schoology, Edmodo e Classcraft). Nos casos dos AVAs com recursos mais automatizados de gamificação, identificaram-se restrições quanto à autoria do professor para estruturar o curso (Khan Academy e Pluralsight). A partir destas limitações, iniciou-se o desenvolvimento do AVA AGILE, gamificado de forma estrutural, como definido por Kapp (2012), com mecânicas de jogos automatizadas e que possibilitasse livre autoria dos professores para elaborar todo o design instrucional dos cursos.

Para experimentação do AGILE, foi definido que o curso seria destinado aos alunos do curso Técnico de Informática, integrado ao Ensino Médio e Concomitante, do 
campus Campos Centro do IFFluminense. A opção por esse público-alvo levou em consideração a possível familiaridade dos alunos com tecnologia e o conhecimento da proposta do curso Técnico de Informática, por parte da primeira autora deste artigo, que atua na área de Tecnologia da Informação e iniciou sua formação no referido curso, na mesma instituição de ensino. Após essa definição, foi elaborado e aplicado um questionário com os alunos do curso Técnico de Informática, tendo como propósito identificar características que pudessem ser importantes para o desenvolvimento do AGILE, como, por exemplo: i) frequência de utilização de jogos digitais, ii) recursos de jogos que mais gostavam; iii) temática desejada para o curso.

O questionário foi respondido por 53 estudantes, dos quais $83 \%$ possuíam entre 15 e 19 anos. Do total de participantes, 67,9\% afirmaram ter o hábito de jogar jogos digitais e $88,7 \%$ informaram que se sentiam interessados em estudar/aprender utilizando aplicativos/sistemas que possuem recursos comuns em jogos, como pontuações, níveis de dificuldade e recompensas. Após a análise dos dados relativa aos recursos de jogos que os alunos mais gostavam, foram considerados para o desenvolvimento do AGILE apenas aqueles que foram apontados como preferidos por mais de $50 \%$ dos participantes, que foram: i) pontuação pelas atividades realizadas $(75,5 \%)$; ii) avanço de níveis de acordo com o desempenho (67,9\%); iii) missões/enigmas a serem resolvidos $(64,2 \%)$; iv) criação de um personagem e possibilidade de fazer com que ele evolua no decorrer das atividades realizadas $(60,4 \%)$; v) interação com outros usuários $(58,5 \%)$; vi) visualização do meu desempenho em relação ao de outros usuários (58,5\%); vii) criação de grupos para realização de tarefas $(56,6 \%)$; viii) ranking de líderes $(54,7 \%)$; ix) ambiente gráfico contextualizado de acordo com a história/narrativa (54,7\%); e x) premiações simbólicas pelo desempenho $(50,9 \%)$. A temática de Lógica de Programação, proposta para o conteúdo do curso, foi bem aceita por $75,5 \%$ dos participantes. Essa temática foi sugerida por ser base para as demais disciplinas de programação. Além disso, de acordo com o sistema acadêmico da instituição na qual a pesquisa está sendo realizada, dos 35 alunos matriculados na disciplina de Fundamentos de Programação, que aborda o conteúdo de Lógica de Programação, do Curso Técnico de Informática concomitante noturno, no $1^{\circ}$ semestre de 2018, 15 eram repetentes.

A partir dos resultados das pesquisas inicialmente realizadas, ou seja, a revisão da literatura e a aplicação do questionário com os alunos do curso Técnico de Informática, foram definidos 12 elementos de jogos que seriam inseridos no AGILE: i) utilização de avatares e nicknames (apelidos) pelos professores e alunos; ii) participação em grupos (equipes); iii) distribuição de badges; iv) coleção de artefatos; v) evolução de níveis; vi) ficha de atributos com características do personagem e conquistas; vii) ranking de líderes individual e por equipe; viii) pontos de experiência (substituindo as notas); ix) narrativa; $\mathrm{x}$ ) missões (substituindo as atividades avaliativas); xi) distribuição de recompensas de acordo com a posição no ranking individual; xii) sistema de feedback.

\subsection{Desenvolvimento}

Para o desenvolvimento do AGILE, foi utilizada a linguagem de programação Ruby com o framework Rails (conhecido como Ruby on Rails). Para que pudesse funcionar em diversos dispositivos digitais, se adequando ao tamanho das telas de desktops, notebooks, smartphones e tablets, o AGILE foi desenvolvido com design responsivo. Além dos recursos de gamificação, o sistema desenvolvido possui recursos comuns em AVAs, como fóruns, chats, pesquisas, criação de eventos, possibilidade de envio de e-mail para os participantes do curso, inserção de materiais em diversos formatos, entre outros.

O AGILE (Figura 1) foi desenvolvido visando criar um ambiente motivador e engajador para os alunos ao mesmo tempo em que os elementos de jogos pudessem ser 
utilizados sem sobrecarregar o trabalho do professor. Assim, alguns elementos de jogos já são predefinidos e automatizados no sistema (rankings, pontuação, distribuição de badges e artefatos, evolução de nível, entre outros) e outros o professor pode escolher utilizar ou não (narrativa, recompensas, formação de equipes, entre outros). Logo, a predefinição de alguns recursos teve como propósito automatizar uma parte do trabalho que o professor teria para utilizar a gamificação.

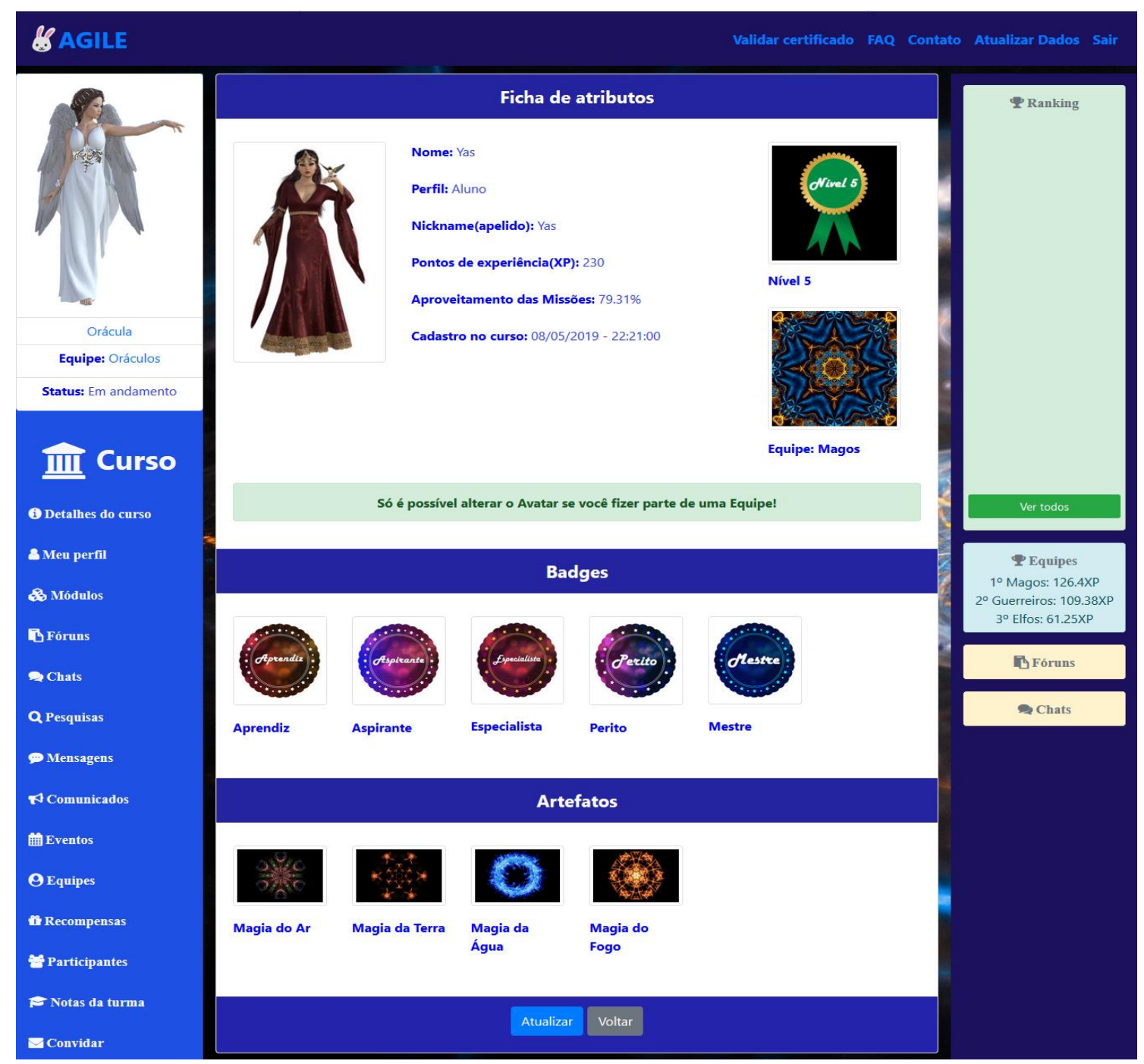

Figura 1- Tela da Ficha de Atributos dos alunos

Fonte: acervo pessoal (figura adaptada para não mostrar o nome dos alunos no Ranking).

Simultaneamente ao desenvolvimento do AGILE, foi elaborado o curso de Lógica de Programação, estruturado em seis módulos. Para introduzir os conteúdos, em cada módulo foram elaborados vídeos que possuíam, em média, dois minutos de duração. $\mathrm{O}$ conteúdo principal de cada módulo foi dividido em tópicos, para os quais foram elaboradas apresentações de slides. As missões (atividades avaliativas) tiveram formato de quiz e deveriam ser realizadas após cada tópico do conteúdo abordado.

\subsection{Avaliação}

Visto que o objetivo principal do AGILE é a aprendizagem, há uma preocupação pedagógica com a inserção dos elementos de gamificação neste e com o design instrucional do curso. Estes devem contribuir para facilitar o processo de aprendizagem, tornando o mesmo mais dinâmico e atrativo para os alunos, mas evitando a distração com aspectos que não são relevantes. 
Para isso, antes da aplicação do curso de Lógica de Programação com o públicoalvo, foi realizada uma pesquisa exploratória, na qual foram aplicados dois questionários. O primeiro destes teve como propósito avaliar a usabilidade do AGILE, de acordo com os componentes expostos por Nielsen (2012). O segundo visou analisar a adequação do design instrucional do curso e dos materiais elaborados, tendo como base cinco princípios da TCAM, que se mostraram mais adequados ao conteúdo do curso, que é predominantemente textual: i) Princípio da Coerência; ii) Princípio da Sinalização; iii) Princípio da Segmentação; iv) Princípio do Pré-treino; e v) Princípio da Personalização.

Cinco pessoas participaram desta pesquisa, todas com formação, em andamento ou concluída, na área de Tecnologia da Informação (um Técnico de Informática e Bacharel em Sistemas de Informação, um aluno do $4^{\circ}$ módulo do Técnico de Informática concomitante; três alunos do $5^{\circ}$ período do Bacharelado em Sistemas de Informação, sendo que um destes também é Técnico de Informática). Os questionários utilizaram a escala Likert, com as opções: Concordo totalmente; Concordo parcialmente; Nem concordo nem discordo; Discordo parcialmente; e Discordo totalmente. Para que os participantes da pesquisa pudessem explorar os recursos do AGILE e os materiais instrucionais do curso, foi disponibilizado um ambiente de testes.

\section{Resultados e discussões}

No questionário que abordou a usabilidade do AGILE, todos os participantes informaram que as páginas do AVA estavam padronizadas (capacidade de aprendizado) e apresentavam textos ou outros recursos que auxiliavam a utilização do sistema (capacidade de aprendizado), além de ser fácil localizar e acessar os cursos (eficiência em uso) e existir a indicação do público-alvo para o qual estes são voltados (eficiência em uso). Também foi unânime a opinião de que a forma como o AGILE está organizado facilita a sua utilização (facilidade de memorização), que são sinalizados os campos de preenchimento obrigatório (baixa taxa de erros) e que a linguagem utilizada deixa clara a ação que precisa ser realizada (baixa taxa de erros).

No entanto, ao serem questionados se as cores utilizadas eram agradáveis e permitiam a correta leitura dos textos (satisfação), um dos participantes concordou parcialmente, alegando que a cor do texto do menu superior não estava sobressaindo em relação à cor de fundo. Outro item que um dos participantes concordou apenas parcialmente foi sobre a existência de recursos suficientes para interação entre os participantes do curso (satisfação), alegando que as salas de chats criadas pelos alunos tinham participação restrita às pessoas da mesma equipe do criador da sala e que deveria existir a possibilidade de criação de salas de chats em que todos os participantes do curso pudessem conversar.

Todos discordaram totalmente a respeito dos recursos de gamificação (avatares, grupos, badges, missões, etc.) terem atrapalhado a utilização do AGILE (eficiência em uso). Contudo, um dos participantes concordou parcialmente que alguns recursos de gamificação sobrecarregaram a interface do AVA (satisfação).

Os principais problemas de usabilidade encontrados, portanto, correspondem ao componente de "satisfação" (Nielsen, 2012), ao contrário dos resultados obtidos nas pesquisas realizadas por Penna et al. (2015) e Zago e Polino (2016), em que os principais problemas de usabilidade se mostraram nos componentes "eficiência em uso" e "baixa taxa de erro". De modo geral, a avaliação da usabilidade do AGILE obteve um resultado positivo. A partir das considerações feitas foram promovidas duas alterações: a cor do texto do menu superior ficou com um tom mais claro para maior contraste com a cor de fundo; a configuração do chat foi alterada para que todos os integrantes do curso pudessem participar das salas de chats, independente da equipe, desde que estas 
fossem criadas pelo professor do curso. Inicialmente, optou-se por aguardar a percepção dos alunos do Técnico de Informática e não alterar a interface gráfica do AGILE em relação à sobrecarga de informações geradas pelos recursos de gamificação, uma vez que apenas um dos participantes teve essa percepção e tal alteração afetaria o período previsto para a experimentação do AGILE com os alunos do curso técnico.

Com relação à pesquisa sobre o design instrucional do curso, todos os participantes consideraram que os materiais elaborados e as atividades propostas estavam adequados à temática do curso e ao público-alvo. Ao serem questionados se as cores, tamanhos e quantidade dos textos, imagens e outros recursos gráficos utilizados estavam adequados para o estudo e a compreensão dos conteúdos (princípio da coerência e segmentação), um dos participantes concordou parcialmente, alegando que havia muito texto em alguns slides das apresentações. O excesso da quantidade de conteúdo no material instrucional também foi percebido na pesquisa feita por Almeida et al. (2014), porém nos materiais elaborados para o curso de Lógica de Programação, o problema não foi a quantidade de informação total por tópico de conteúdo como nos OAs analisados por Almeida et al. (2014), mas o excesso de informação por slide nas apresentações, provocado pela tentativa de reduzir o tamanho final do material instrucional.

Com relação aos vídeos introdutórios (princípio do pré-treino) de cada módulo, todos afirmaram que auxiliaram na compreensão inicial do conteúdo. A percepção de todos os participantes da pesquisa também foi de que a sequência do conteúdo abordado era coerente e que havia recursos suficientes para destacar o conteúdo abordado e os aspectos mais importantes destes (princípio da sinalização), assim como de que a linguagem adotada nos materiais instrucionais, utilizando algumas vezes personagens e fazendo questionamentos, era agradável e adequada (princípio da personalização). Com base nos dados coletados, foram realizadas alterações nas apresentações de slides, com melhor distribuição dos textos, a partir da inclusão de mais slides. No geral, o resultado da avaliação do material instrucional elaborado também foi considerado satisfatório.

\section{Considerações finais}

Visou-se desenvolver um AVA gamificado que possibilitasse proporcionar motivação, interesse, engajamento e diversão aos alunos durante o processo de aprendizagem. Houve também uma preocupação com a perspectiva do professor ao utilizar o AGILE, buscando automatizar alguns recursos de gamificação para reduzir o esforço na configuração do curso, mas, ao mesmo tempo, garantindo a autoria e a liberdade para estruturá-lo, conforme este achar mais adequado ao público-alvo e ao conteúdo. Desta forma, os principais diferenciais do AGILE são: a presença de 12 elementos de jogos, ou seja, não foram utilizados apenas os três recursos de gamificação mais comuns, conhecidos como PBL; a automatização da utilização de vários destes elementos de jogos; e possibilitar a livre autoria do professor para estruturar os cursos.

Apesar de o curso elaborado para a experimentação abordar Lógica de Programação, o AGILE possibilita a realização/inserção de cursos de diversas áreas do conhecimento e temáticas. A avaliação relativa à usabilidade do AGILE e ao design instrucional do curso teve resultados positivos e contribuiu para aperfeiçoar tanto o recurso de chat do AVA como o material instrucional do curso.

A próxima etapa da pesquisa é a efetivação do curso de Lógica de Programação, com o público-alvo no AGILE. Objetivando identificar a percepção dos alunos, ao final do curso, estes responderão a um questionário sobre os recursos de gamificação e sobre o material instrucional. Além disso, serão registrados os acessos de cada usuário e sua navegação pelas páginas do AGILE, entre outras informações. Os dados serão coletados mediante o aceite dos "termos de uso" do AGILE e do "termo de consentimento livre e esclarecido". Estes dados, ao serem minerados, poderão ser utilizados para mapear os 
perfis e as preferências dos usuários, identificando os recursos mais engajadores. Essa coleta visa promover melhorias futuras no AGILE, como o desenvolvimento e a utilização de recursos de gamificação de acordo com o perfil do usuário.

\section{Referências}

ALMEIDA, R. R. et al. Avaliação de objetos de aprendizagem sobre o sistema digestório com base nos princípios da Teoria Cognitiva de Aprendizagem Multimídia. Ciência e Educação, v. 20, n. 4, p. 1003-1017, 2014.

ALVES, F. Gamification: como criar experiências de aprendizagem engajadoras: um guia completo do conceito à prática. 2. ed. São Paulo: DVS Editora, 2015.

BISSOLOTTI, K. et al. Potencialidades das mídias sociais e da gamificação na educação a distância. RENOTE, v. 12, n. 2, p. 1-11, 2014.

BRAZIL, A. L.; BARUQUE, L. B. Gamificação aplicada na graduação em jogos digitais. In: CONGRESSO BRASILEIRO DE INFORMÁTICA NA EDUCAÇÃO (CBIE), 4., 2015. SIMPÓSIO BRASILEIRO DE INFORMÁTICA NA EDUCAÇÃO (SBIE), 26., 2015. Anais eletrônicos... Recife: 2015.

FADEL, L. M. et al. Gamificação na educação. São Paulo: Pimenta Cultural, 2014. FLORES, T. H. et al. Identificação dos Tipos de Jogadores para a Gamificação de um Ambiente Virtual de Aprendizagem. RENOTE, v. 14, n. 1, p. 1-10, 2016.

GIL, A. C. Métodos e técnicas de pesquisa social. 6. ed. São Paulo: Atlas, 2008. KAPP, K. M. The Gamification of Learning and Instruction: Game-based Methods and Strategies for Training and Education. San Francisco: Pfeiffer, 2012.

KLOCK, A. C. T. et al. Análise das técnicas de Gamificação em Ambientes Virtuais de Aprendizagem. RENOTE, v. 12, n. 2, p. 1-.10, 2014.

MAYER, R. E. The promise of multimedia learning: using the same instructional design methods across different media. Learning and Instruction, v. 13, n. 2, p. 125-139, 2003.

MAYER, R. E. Applying the Science of Learning to Multimedia Instruction. The psychology of learning and motivation, v. 55, p. 77-108, 2011.

NEVES, R. F. et al. A imagem da célula em livros de biologia: uma abordagem a partir da teoria cognitivista da aprendizagem multimídia. Investigações em Ensino de Ciências, v. 21, n.1, p. 94-105, 2016.

NIELSEN, J. Usability 101: Introduction to Usability. Fremont: Nielsen Norman Group, 2012. Disponível em: <www.nngroup.com/articles/usability-101-introductionto-usability>. Acesso em: 23 jan. 2019.

OGAWA, A. N. et al. Análise sobre a gamificação em Ambientes Educacionais.

RENOTE, v. 13, n. 2, p. 1-10, 2015.

PENNA, J. T. C. et al. Apreciação da Usabilidade do Moodle: Um Estudo de Caso no Contexto do Ensino Fundamental. In: SIMPÓSIO BRASILEIRO DE INFORMÁTICA NA EDUCAÇÃO (SBIE), 26., 2015, Maceió. Anais eletrônicos... Maceió: SBIE, 2015. SOUZA, F. J. R. A importância do design no desenvolvimento de ambientes virtuais de aprendizagem. Revista Internacional de Formação de Professores (RIFP), v. 3, n.1, p.227-244, 2018.

TAROUCO, L. M. R. et al. Mídias na educação: a pedagogia e a tecnologia subjacentes. Porto Alegre: Editora Evangraf/Criação Humana, UFRGS, 2017. TODA, A. M. et al. Desafios para o Planejamento e Implantação da Gamificação no Contexto Educacional. RENOTE, v. 15, n. 2, p. 1-10, 2017.

ZAGO, G. S.; POLINO, C. A. Interfaces, Usabilidade e Ambientes Virtuais de Aprendizagem: uma Avaliação Heurística do AVA UFPel. Revista Cadernos da Escola de Comunicação, v. 1., n. 14, p. 78-92, 2016. 